\title{
Qualitative Determination of Citalopram and Escitalopram in whole human blood using liquid- liquid extraction and GC/GC-MS
}

\author{
Sneha Yadav \\ Assistant Professor Dept. of Forensic Science, Galgotias University, Greater Noida, Uttar Pradesh
}

Corresponding Author:

Email: snehay2108@gmail.com

\begin{abstract}
Citalopram is a antidepressant drug, generally prescribed for the treatment of major depression. It comes under the SSRI's class (selective serotonin reuptake inhibitor). It is frequently used off-label to treat anxiety, panic disorder, obsessive compulsive disorder, premenstrual dysphoric disorder.

As per forensic point of view citalopram which is non tricyclic antidepressant is generally prescribed for treating depression because of its undesirable side effects than classical tricyclic antidepressants so they are nowadays more commonly used as the drugs of first choice and therefore the chance of detecting it in the biological materials analyzed in toxicology division is high. Present study has been structured with an aim to test citalopram, present in blood and the comparison of citalopram and escitalopram which are the enantiomers. For extraction of citalopram from blood, sodium tungstate method was used followed by liquid- liquid extraction.

The alkaline extract of blood obtained from Sodium Tungstate was used for identification by color tests. Citalopram is basic in nature, but it does not respond to commonly used color test for benzodiazepines/alkaloids. Hence various color tests were performed which were reported in literature out of which marquis \& mandelin gives positive result. cobalt thiocyanate has also given positive test for presence of citalopram which can be used in future for testing citalopram.

Further the identification of the drug was carried out by thin layer chromatography by various solvent systems. In search for different solvent systems various combinations of solvents were tried and reproducible results were produced. For the separation of citalopram \& Escitalopram solvent system Toluene: Acetonitrile: methanol has given the good Rf values and reproducible.

Results: Other instrumentation technique, like UV visible spectroscopy, Gas liquid chromatography (GLC), GC-MS was also used for the qualitative analysis.
\end{abstract}

Keywords: Citalopram, Escitalopram, Extraction, Tricyclic antidepressants.

\section{Introduction}

Citalopram is a basic drug, generally prescribed for the treatment of anxiety and major depression. It is also used successfully for hypersexuality in early Alzheimer Disease.

Citalopram its chemical name is (3 (Dimethylamino) propyl) 1(4-fluorophenyl) 1,3 dihydroisobenzofuran 5carbonitrile hydrobromide. ITS IS AN optically active molecule. The drug citalopram is a combination of two enantiomeric forms, $(R)(-)$ citalopram \& $(S)(+)$ citalopram. The former one is pharmacologically inactive and later is pharmacologically active and hence it is responsible for the drug, showing its antidepressant activity later one is known as Escitalopram.

Citalopram along with its Metabolites are racemic compounds (+) enantiomer of citalopram is active \& plays role in inhibition of serotonin reuptake \& its accounts for $24 \%$ to $49 \%$ of total plasma citalopram level, but R (-) form do not play any role in inhibition of serotonin.

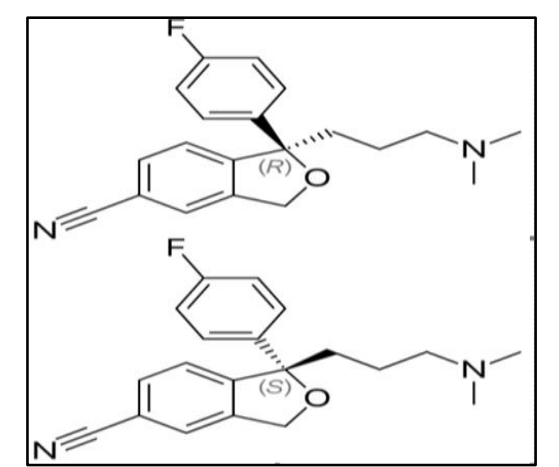

Fig. 1(R)-(-)-citalopram (top), (S)-(+)-citalopram (bottom)

Common Name: citalopram

Brand Names: Akarin (Denmark, Nycomed)

C Pram S (India)

Celapram (Australia, ${ }^{l}$ New Zealand),

Celexa (U.S. and Canada, Forest Laboratories, Inc.)

Celica (Australia)

Ciazil (Australia, New Zealand)

Cilate (South Africa)

Cilift (South Africa)

Cimal (South America, by Roemmers and Recalcine)

Cipralex (South Africa)

Cipram (Turkey, Denmark, H. Lundbeck A/S) 
Cipramil (Australia, Brazil, Belgium, Finland, Germany, Netherlands, Iceland, Ireland, Israel, Norway, Sweden, United Kingdom, New Zealand, South Africa, Russia)

Cipraned, Cinapen (Greece)

Ciprapine (Ireland)

Molecular Formula: $\mathrm{C}_{20} \mathrm{H}_{22} \mathrm{BrFN}_{2} \mathrm{O}$

Molecular Mass: $405.311 \mathrm{~g} / \mathrm{mol}$

Half Life: 3 hours

Action and use: used as Antidepressant, antianxiety, in treatment of Insomnia, Panic Disorder.

Symptom of Overdose: Most common symptom following mild overdose include tiredness, confusion, dizziness, stomach pain, sweaing, nausea, sinus tachycardia, tremors \& convulsions, withdrawal symptoms: There is anecdotal evidence that citalopram may cause symptom nausea, vomiting, insomnia, somnolence, dizziness, asthenia, headache.

Metbolism: It is metabolized in the liver mostly by CYP2C19 (CYTOCHROME P450 2C19) an enzyme,it is a liver enzyme. Its metabolites are desmethyl citalopram \& Didesmethyl citalopram Metabolised in Liver by $2 \mathrm{~N}$ Demethylation steps.

Citalopram to Demethylcitalopram (DCT)in presence of CYP2C19 than from DCT it is converted to Didemethal citalopram (DDCT).Oxidation occurs by Monoamine oxidases A \&B and aldehyde oxidases, which leads to formation of Propionic acid derivative and citalopram $\mathrm{N}$-oxide,

Citalopram is at least 4 times more potent than DCT and13 times more potent than DDCT in inhibiting the serotonin (5HT). Citalopram is a serotonin reuptake inhibitor (SRI),it is a type of drug that act as a reuptake inhibitor of) 5-Hydroxy tryptamine (5HT) a neurotransmitter serotonin. This leads to an acute increase in extracellular 5-HT levels in animals following citalopram $10 \mathrm{mg} / \mathrm{kg}$ twice daily.

Pharmacokinetics: The peak plasma levels occur 2 to 4 hours after single or multiple dose, citalopram absorption is unaffected by food, the oral bioavailability is $80 \%$ approx. \& this peak plasma concentration follow daily dose of $40 \mathrm{mg}$ is $311 \mathrm{nmol} / \mathrm{L}$.

Elimination: The distribution time occurs for 10 hour and the citalopram follows a biphasic elimination.

Half line for citalopram -30 to 35 hour

Half life for DCT- 50 HOUR

Half life for DDCT- 100 HOUR Upto $23 \%$ of dose citalopram is excreted unchanged in urine.

\section{Case Study}

A 54-Year-old woman presented to emergency unit with altered consciousness and under the influence of alcohol, she had a medical history of psychotic depression treated with citalopram $20 \mathrm{mg} /$ day and zopiclone $7.5 \mathrm{mg} /$ day. Rapid urine toxicology screen was negative for tricyclic antidepressants, benzodiazepines, cocaine or opiate using a HPLC/UV method $1^{\text {st }}$ serum citalopram level was 5,88mg/l (High concentration responsible for unstable clinical situation) Activated charcoal was administered $5 \mathrm{~g} \&$ monitoring on citalopram level was started.

\section{Objective}

1. Extraction of citalopram blood

2. Detection of citalopram in blood by color test \& tlc by new solvent system.

3. Comparison of citalopram and escitalopram

\section{Methods and Materials}

1) Requirement of glassware's Glasswares

2) Stoppered borosil

3) Test tubes (10ml)

4) borosil test tubes $10 \mathrm{ml}$,

5) borosil beakers $(100 \mathrm{ml}, 250 \mathrm{ml})$

6) Glass rod,

7) Funnel,

8) Conial Flask $(250 \mathrm{ml})$

9) Glass drooper,

10) Glass plates $(10 * 10)$

11) Solvent chamber

12) Silica Crucible,

13) Borosil Meauring cyclinder (10ml, 100ml),

14) spray Bottle (atomizer),

15) spot plate,capillary tubes etc.

\section{Chemicals}

Acetic acid, ethanol, Methanol, dichloromethane, diethylether, ammonia, sodium tungstate, sulphuric acid, hydrochloric acid, nitric acid, silica gel, Cobaltthiocyanate, Formaldehyde Bismuth nitrate, potassium iodide, butanol, ethaylacetate, Toluene.

\section{Methods}

Preparation of Sample

Description of Exhibit

II. Blood Sample

Description of Tablet (Spiked Drug)

I. Description about Pack of CITALOPRAM \& ESCITALOPARM Tablet

CITALOPRAM

Brand name CPRAMS

Color: Pink

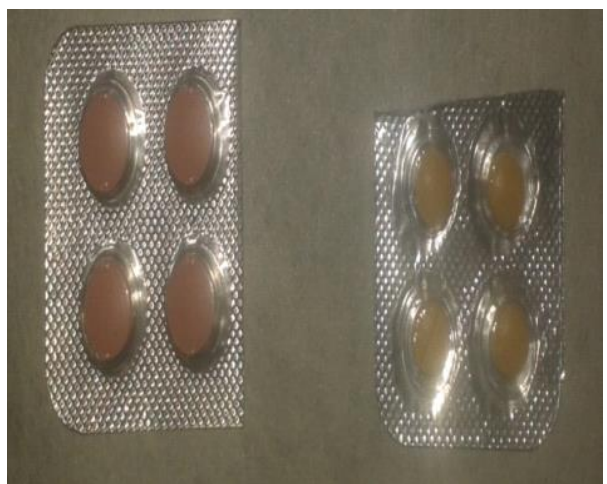

Fig. 2: Cpram S Quantity: 10 TABLETS (10Mg)

Escitalopram 
Brand name: NEXITO 5

Color: Yellow

Quantity: 5mg (10 tablets)

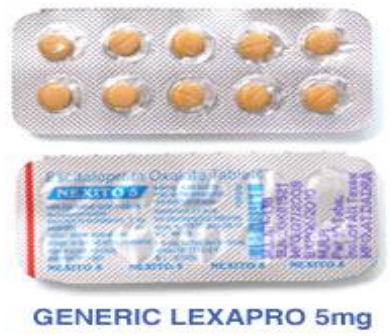

Fig. 3: Spiking Of drug into Exhibit

I. Drug Spiked into Samples \& method of Spiking.

Preparation of Standard

I. Description of Standard

Extraction Method

From Blood: Sodium Tungstate method

Identification Method

\subsubsection{Preliminary Identification}

I. Color test

5.2.4.2 Confirmatory Identification

I. Chromatographic techniques

1) Thin Layer Chromatography (TLC)

II. Spectroscopic technique

1) UV Visible spectroscopy

III. Hyphenated technique

1) GC

2) GC-MS

Preparation of Sample: Description of samples

The following Drug samples "citalopram" \& Escitalopram was provided from, Indian pharmacopeia commission.

C PRAM S 10mg - 10 tablets

ESCITALOPRAM $(5 \mathrm{mg}) 10$ tablets

Spiking Of drug into Exhibit

Drug Spiked into Samples \& method of Spiking: The blood sample was collected from "Jaipur Golden Hospital". Carefully transferred $10 \mathrm{ml}$ of blood in beaker of $250 \mathrm{ml}$ and $30 \mathrm{mg}$ of citalopram tablet was spiked by after crushing it into powered form.

Preparation of Standard: Preparation of standard of Drugs.

$30 \mathrm{ml}$ of 1000ppm solution of each of the provided drug were prepared by dissolving $30 \mathrm{mg}$ of drug in 30 $\mathrm{ml}$ of ethanol i.e. $30 \mathrm{mg} / 30 \mathrm{ml}$.

Table 1

\begin{tabular}{|l|l|}
\hline Standard drugs & $\begin{array}{l}\text { Concentration } \\
(\mathbf{p p m})\end{array}$ \\
\hline Citalopram & 1000 \\
\hline Escitalopram & 1000 \\
\hline
\end{tabular}

Extraction Method

From Blood

Sodium Tungstate method

Liquid-Liquid extraction

Identification Method

\section{Preliminary Identification}

I. Color test

Confirmatory Identification

1) Thin Layer Chromatography (TLC)

2) UV Visible spectroscopy

3) GC-MS

Extraction of Drug From Blood

Sodium Tungstate Methods: The $10 \mathrm{ml}$ was taken into a $250 \mathrm{ml}$ beaker. 1 gram of sodium tungstate was added to it. Few drops of sulphuric acid was added The mixture is then heated in boiling water bath for 3 hours. After 3 hours there is complete digestion and lysis of $\mathrm{RBC}$ and clear straw color liquid will be seen and lysed cells would be settled down.

The Mixture is cooled slightly and filtered through fliter paper. The filtrate was taken into $250 \mathrm{ml}$ separating funnel.

\section{Liquid Liquid Extraction}

To the $250 \mathrm{ml}$ of separating funnel $10-15 \mathrm{ml}$ of filtrate was added and $20-50 \mathrm{ml}$ of diethyl ether was added and shaken for 5 minutes and separated. again 50 $\mathrm{ml}$ of diethyl ether is added to the acidic layer shaken for 5 minutes and separated. The ether layers are combined.

The aqueous solution remaining in separating funnel after separation of ether layer was made alkaline by addition of ammonium hydroxide. The aqueous layer was taken into $250 \mathrm{ml}$ of separating funnel and 50 $\mathrm{ml}$ of dichlormethane is added \& shaken for 5 minutes. The organic layer is separated. The extraction is repeated thrice.The organic layer after separation are combined. The extract was collected and passed through the anhydrous sodium sulphate for absorbing excess moisture and then a clear filtrate was collected in china dish. Now the china dish was putted on water bath,, evaporated the organic layer and residue was remain.

After evaporation of solvent. the residue was dissolved in $10 \mathrm{ml}$ of ethanol \& subjected to analysis for confirmation of drug.

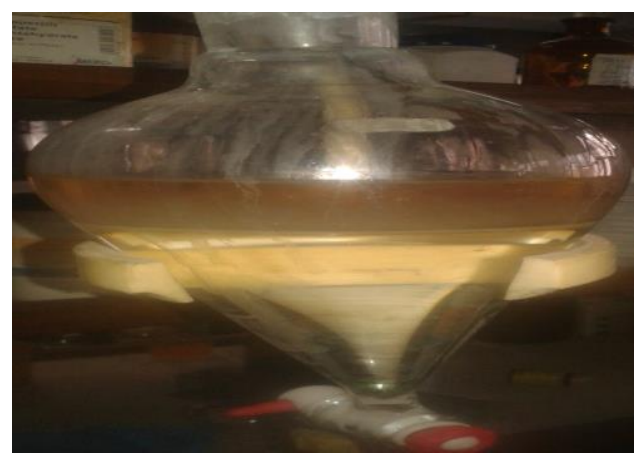

Fig. 4: Liquid -Liquid Extraction

Preliminary Examination: It is a preliminary step in analysis of any compound. It is frequently used to determine the broad category of groups under which our sample can be placed. 


\section{Color tests}

\section{Marquis Test}

Reagent: Dissolve I volume of formalin in 9 volume of concentrated sulphuric acid

Procedure

$1 \mathrm{ml}$ of blood extract was taken into a spot tile and added 2 drops of marquis reagent and observed the color.

Observation: Yellow color observed

\section{Positive for Citalopram}

Mandelin Reagent: Dissolve 0.5 -1 g of ammonium vanadte in $100 \mathrm{ml}$ of concentrated sulphuric acid.

Procedure

I $\mathrm{ml}$ of extract was taken in a apot tile and added 1 drops of mandelin reagent the color was brownish green observed.

\section{Positive for Citalopram}

Frohde: Test: Preparation of reagent: $0.5 \mathrm{gm}$ Ammonium Molybdate is dissolved in $100 \mathrm{~mL}$ distilledwater.

Method: To the dried extract, add the reagent, mixed thoroughly and color was observed.

Observation: No colorobserved.

\section{Results}

\section{Negativeforcitalopram}

Dragendorff Test: Reparation of reagent: Dissolve 1 gm Bismuth Subnitrate in $3 \mathrm{ml} \mathrm{Conc.} \mathrm{HCl}$ and diluted to $20 \mathrm{~mL}$ using distilled water. $1 \mathrm{gm}$ Potassium Iodide was then added to above solution.

Method: To the dried extract, add the reagent, mixed thoroughly and color was observed.

Observation: Orange yellow color was observed.

\section{Results: Positive for Citalopram}

\section{Ferric chloride Reagent Test}

Preparation of Reagent:- Dissolve $4.50 \mathrm{~g}$ of ferric chloride hexahydrate and $2.5 \mathrm{~mL}$ of hydrochloric acid in water, and dilute to $100 \mathrm{~mL}$ with water.

Method: To the dried extract, add the reagent, mixed thoroughly and color was observed.
Observation: No color change was observed.

\section{Results: NEGATIVE FOR CITALOPRAM}

FPN Reagent Test: Preparation of reagent: Mix $5 \mathrm{ml}$ of aqueous ferric chloride solution, $45 \mathrm{ml}$ of aqueous Perchloric acid and $50 \mathrm{ml}$ of aqueous nitric acid.

Method: To the dried extract, add the reagent, mixed thoroughly and color was observed.

Observation: No color change was observed.

\section{Results}

\section{Negative for citalopram}

Cobalt thiocyanate Test: Reagent Dissolve $1.5 \mathrm{~g}$ of cobalt thiocyanate in $29 \mathrm{ml}$ of water.

Table 2: I ml of extract was taken into a spot tile and $1 \mathrm{ml}$ of extract was assed and color was observed

\begin{tabular}{|l|c|l|}
\hline Compound & $\begin{array}{l}\text { Colour } \\
\text { Observed }\end{array}$ & Reaction time \\
\hline Citalopram & Blue & Instantaneous \\
\hline Escitalopraam & Blue & Instantaneous \\
\hline Sample & Blue & Instantaneous \\
\hline Sample & Blue & Instantaneous \\
\hline
\end{tabular}

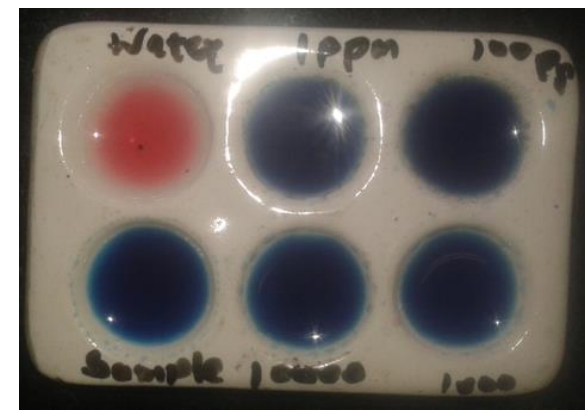

Fig. 5

Cobalt Thiocyanate reacts with amines and gives colour according to the concentration of compound, various amines were tested with the reagent.

Table 3

\begin{tabular}{|c|l|l|}
\hline S. No & Compund & Colour Observed \\
\hline 1 & Diethylamine & BLUE Precipitate than solution turn brown \\
\hline 2 & Isopropylamine & Blue green precipitate \\
\hline 3 & Dethanolamine & BLUE Precipitate than solution turn brown \\
\hline 4 & ethylenepentamine & Blue precipitate than solution turn brown \\
\hline 5 & Ethylenediamine & Blue precipitate than solution turn brown \\
\hline 6 & Tetraethylene pentamine & Blue precipitate than solution turn brown \\
\hline 7 & Diphenylamine & Pink solution(color of reagent) \\
\hline 8 & Triethylamine & Blue green color \\
\hline 9 & Water & Pink solution ( reagent color) \\
\hline 10 & Samples & Blue color \\
\hline 11 & Standard & Blue color \\
\hline
\end{tabular}




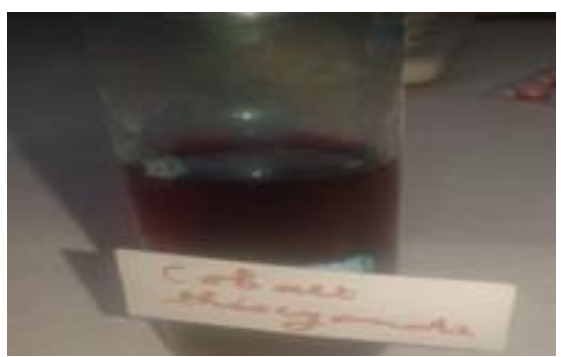

Fig. 6

Fig. 7
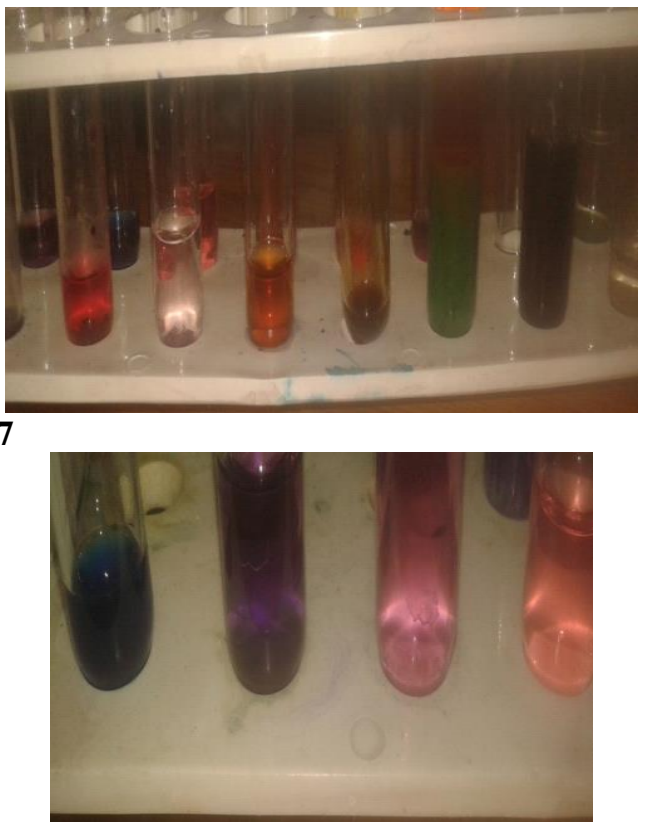

Fig. 8: Various Amines Tested with cobalt

Thiocyanate

Thin-Layer Chromatographic Technique: Thin layer chromatography or TLC is a chromatography technique used to separate non votalitle mixture into its constituents, Thin layer chromatography or TLC, is a solid-liquid form of chromatography where the stationary phase is normally a polar absorbent and the mobile phase could be a single solvent or combination of solvents like binary solvents. Ismailof and Schraiber in 1938 discvered TLC. Technique developed by Meinhard and hall 91949), Kirchner, Miller and Keller (19510,Mattier (1952) and Egon Stahal (1958).TLC is performed on a sheet of glass, plastic, or aluminium foil, which is coated with a thin layer of adsorbent material, mainly silica gel, aluminium oxide cellulose. The layer of adsorbent is known as stationary phase, that's why it is called as Thin layer chromatography.

Principle: TLC function on the same principle as all chromatography a compound have different affinities for the mobile and stationary phases and this affects the speed at which it migrates. Different compounds in sample of mixtures travel at different rates due to differences in their attraction to the stationary phase, because of differences in solubility in the solvent, by changing the solvent. or by varying the ratios of solvents, the separation of components measured by the Rf value could be adjusted.

Preparation of TLC Plates: Tlc plates were prepared by Dissolving silica gel $G$ and distilled water in 1:2. the slurry was poured on glass plates in one motion. plates were allowed to dry at room temperature and then lept in oven at $90^{\circ} \mathrm{C}$ for $1-2$ hour.

Spotting of samples and standard on TLC Plates: The $10 \mu$ of standard solution of drugs were spotted on TLC plate along with the extracted blood sample by using micropipette. The spotting was done just above the $2 \mathrm{~cm}$ from the base edge of TLC plates.

Table 4

\begin{tabular}{|l|c|c|}
\hline Mobile Phase & Standard Rf & Blood Extract Rf \\
\hline $\begin{array}{l}\text { Ethylacetate: } \\
\text { (13:3:2) } \\
\text { butanol: Ammonia }\end{array}$ & 0.878 & 0.878 \\
\hline $\begin{array}{l}\text { Ethylacetate: } \\
\text { (60:35:5) } \\
\text { methanol: formic } \\
\text { acid }\end{array}$ & 0.658 & 0.647 \\
\hline $\begin{array}{l}\text { Methanol: (60:40) } \\
\text { Butanol }\end{array}$ & 0.41 & 0.41 \\
\hline $\begin{array}{l}\text { Ethylacetate: (13:7) } \\
\text { Butanol: }\end{array}$ & 0.68 & 0.68 \\
\hline $\begin{array}{l}\text { Toluene } \\
\text { (3:3.5:3.5): }\end{array}$ & 0.57 & 0.694 \\
$\begin{array}{l}\text { Acetoniotrile: } \\
\text { Methanol }\end{array}$ & & \\
\hline $\begin{array}{l}\text { Ethylacetate: } \\
\text { benzene ammonia } \\
\text { 7:5:3) }\end{array}$ & NIL & NIL \\
\hline
\end{tabular}

After the complete development, the plate was taken out and allowed to dry it at room temp. Till evaporation of solvent completely. After complete dryness, the plate was visualized under UV at $254 \mathrm{~nm}$ followed by spraying of following spraying reagent Plate in solvent system (ethylacetate: methanol: ammonia)

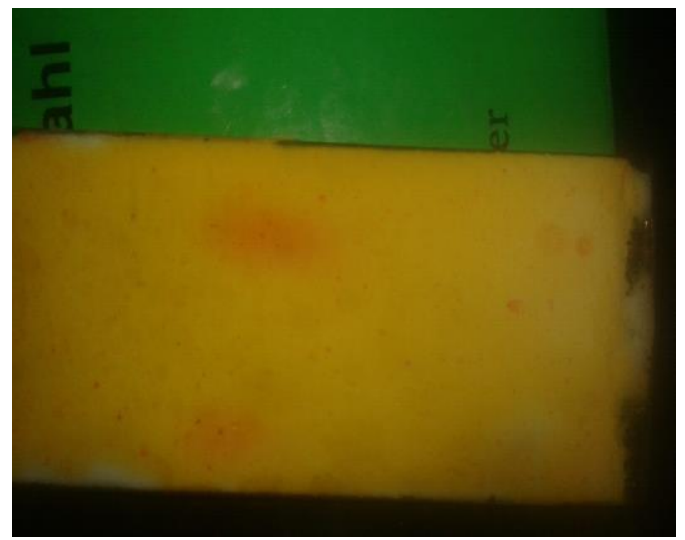

Fig. 9 


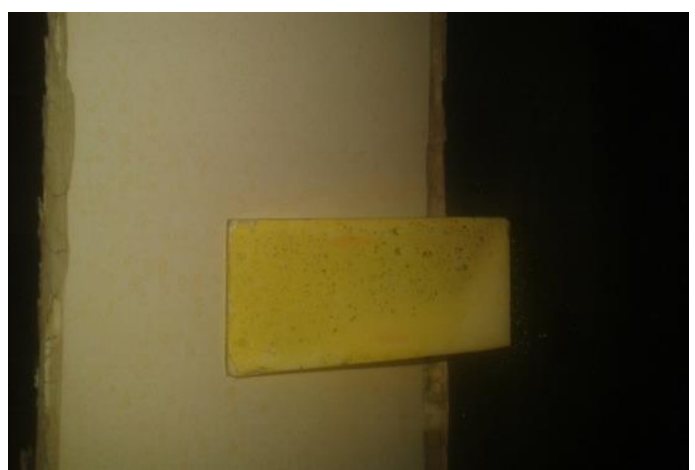

Fig. 10: Citalopram Escitalopram

Plate In Solvent System-Toluene: Acetonitrile: Methanol.

\section{Visualization of TLC Plates}

1) UV- Light Source: Observed the developed TLC plate under UV light source at $254 \mathrm{~nm}$. There is Green background with light color spots.

2) Iodine Fuming Chamber: 10g Sublimed Iodine in a beaker covered with aluminium foil kept for 15 minutes, for saturated the iodine vapours in the chamber after that kept the developed TLC plate on clean \& dried Iodine Fuming Chamber. Then covered the chamber with its lid and observed the spots on TLC plates after 5 minutes.

Observation: A dark yellow color spot was observed.

3) Dragen-dorff's Reagent: $1 \mathrm{~g}$ of bismuth subnitrate is dissolved in $3 \mathrm{ml}$ of $10 \mathrm{~m}$ of hydrochloric acid.It is diluted to $20 \mathrm{ml} .1 \mathrm{~g}$ of potassium iodide is dissolved in it. If black precipitate of bismuth tri-iodide separates, It is dissolved in $2 \mathrm{M}$ hydrochloric acid.

\section{Observation - orange color spot observed}

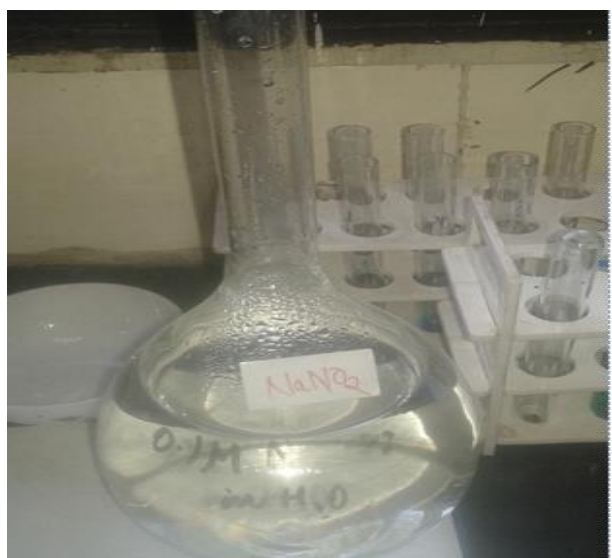

Fig. 11: 0.1M sodium nitrite spray

$6.9 \mathrm{~g}$ of sodium nitrite was dissolved in $1000 \mathrm{ml}$ of distilled water.

After spraying the plates with dragen-dorff's plates were sprayed with sodium nitrite spray

Observation orange color spots become little intense For comparison of citalopram \& escitalopram: The standard solutions of drugs of citalopram and escitalopram were spotted on TLC plates and run on different combinations of solvents in order to get the good separation of these two enantiomers. After the development of TLC plates which were run upto $10 \mathrm{~cm}$ from its base were removed and dry it at room temperature

\section{Table 5}

\begin{tabular}{|l|c|c|c|}
\hline S.NO & Ratio & CITALOPRAM & ESCITALOPRAM \\
\hline $\begin{array}{l}\text { Ethylacetate: } \\
\text { benzene }\end{array}$ & $6: 6$ & 1 & 0.88 \\
\hline & $6: 6$ & 0.99 & 0.87 \\
\hline & $6: 6$ & 0.88 & 0.89 \\
\hline & $6: 6$ & 0.996 & 0.88 \\
\hline & $6: 6$ & 1 & 0.88 \\
\hline & $6: 6$ & 0.99 & 0.99 \\
\hline & $6: 6$ & 0.99 & 0.88 \\
\hline & $6: 6$ & 0.87 & 0.85 \\
\hline & $6: 6$ & 0.75 & 0.89 \\
\hline & $6: 6$ & 0.79 & 0.99 \\
\hline Methanol: Butanol & $60: 40$ & 0.4 & 0.4 \\
\hline & $60: 40$ & 0.39 & 0.22 \\
\hline & $60: 40$ & 0.55 & 0.41 \\
\hline & $60: 40$ & 0.38 & 0.35 \\
\hline & $60: 40$ & 0.3 & 0.4 \\
\hline & $60: 40$ & 0.41 & 0.42 \\
\hline & $60: 40$ & 0.399 & 0.412 \\
\hline & $60: 40$ & 0.412 & 0.44 \\
\hline & $60: 40$ & 0.41 & 0.39 \\
\hline & $60: 40$ & 0.29 & 0.3 \\
\hline Ethylacetate: & $60: 35: 5$ & 0.658 & 0.647 \\
\hline
\end{tabular}




\begin{tabular}{|c|c|c|c|}
\hline $\begin{array}{l}\text { methanol: } \\
\text { formic acid }\end{array}$ & & & \\
\hline & & 0.559 & 0.646 \\
\hline & & 0.549 & 0.55 \\
\hline & & 0.64 & 0.66 \\
\hline & & 0.58 & 0.61 \\
\hline & & 0.66 & 0.63 \\
\hline & & 0.61 & 0.63 \\
\hline & & 0.59 & 0.62 \\
\hline & & 0.57 & 0.55 \\
\hline & & 0.66 & 0.63 \\
\hline $\begin{array}{l}\text { Ethylacetate: } \\
\text { butanol: } \\
\text { Ammonia }\end{array}$ & $13: 3: 2$ & 0.878 & 0.878 \\
\hline & & 0.75 & 0.825 \\
\hline & & 0.85 & 0.75 \\
\hline & & 0.458 & 0.51 \\
\hline & & 0.5 & 0.49 \\
\hline & & 0.77 & 0.85 \\
\hline & & 0.79 & 0.86 \\
\hline & & 0.83 & 0.85 \\
\hline & & 0.9 & 0.825 \\
\hline & & 0.86 & 0.85 \\
\hline $\begin{array}{l}\text { Ethylacetate: } \\
\text { Butanol: } \\
\text { Ammonia }\end{array}$ & $75: 15: 5$ & 0.95 & 0.98 \\
\hline & & 0.94 & 0.93 \\
\hline & & 0.89 & 0.9 \\
\hline & & 0.97 & 0.99 \\
\hline & & 0.91 & 0.92 \\
\hline & & 0.934 & 0.99 \\
\hline & & 0.9 & 0.98 \\
\hline & & 0.97 & 0.96 \\
\hline & & 0.96 & 0.95 \\
\hline $\begin{array}{l}\text { Ethylacetate: } \\
\text { Benzene: Ammonia }\end{array}$ & $7: 5: 3$ & NIL & NIL \\
\hline $\begin{array}{l}\text { Ethylacetate: } \\
\text { Methanol: } \\
\text { Ammonia }\end{array}$ & $85: 10: 5$ & 0.822 & 0.696 \\
\hline & & 0.81 & 0.70 \\
\hline & & 0.82 & 0.68 \\
\hline & & 0.8 & 0.699 \\
\hline & & 0.799 & 0.68 \\
\hline & & 0.833 & 0.696 \\
\hline & & 0.834 & 0.71 \\
\hline & & 0.88 & 0.7 \\
\hline & & 0.810 & 0.7 \\
\hline & & 0.81 & 0.696 \\
\hline $\begin{array}{l}\text { Hexane: Benzene } \\
\text { :methanol: } \\
\text { ethylacetate } \\
\text { :ammonia }\end{array}$ & $2: 2: 2: 3: 1$ & nil & nil \\
\hline $\begin{array}{l}\text { Cyclohexane; } \\
\text { propanol: } \\
\text { ammonia }\end{array}$ & $5: 4: 1$ & 1 & 1 \\
\hline Methanol: & $4: 2: 4$ & 0.87 & 0.87 \\
\hline
\end{tabular}




\begin{tabular}{|l|l|l|l|}
\hline $\begin{array}{l}\text { ormic acid: } \\
\text { butanol }\end{array}$ & & & \\
\hline & & 0.86 & 0.85 \\
\hline & & 0.87 & 0.86 \\
\hline & & 0.87 & 0.87 \\
\hline & & 0.87 & 0.87 \\
\hline & & 0.85 & 0.84 \\
\hline & & 0.79 & 0.82 \\
\hline & & 0.79 & 0.83 \\
\hline & & 0.86 & 0.86 \\
\hline $\begin{array}{l}\text { Toluene: } \\
\text { Acetoniotrile: } \\
\text { Methanol }\end{array}$ & $3: 3.5: 3.5$ & 0.81 & 0.517 \\
\hline & & & 0.694 \\
\hline & & 0.516 & \\
\hline & & 0.511 & 0.666 \\
\hline & & 0.516 & 0.683 \\
\hline & & 0.518 & 0.611 \\
\hline & & 0.517 & 0.688 \\
\hline & & 0.516 & 0.694 \\
\hline & & 0.517 & 0.688 \\
\hline & & 0.516 & 0.694 \\
\hline & & 0.544 & 0.693 \\
\hline & & & 0.699 \\
\hline
\end{tabular}

Om the basis of above result and Rf it can be seen that good separation is achieved in solvent system toluene: acetonitrile: methanol (3:3.5:3.5) ethylacetae: Butanol: Ammonia(13:3:2)
Standard Deviation

$$
\sigma=\sqrt{\frac{1}{N} \sum_{i=1}^{N}\left(x_{i}-\mu\right)^{2}}
$$

Where $\sum$ means "sum of", $\mathrm{x}$ is a value in the data set, $\mathrm{x}$ - is the mean of the data set, and $n$ is the number of data points.

Table 6

\begin{tabular}{|l|l|l|l|l|l|}
\hline $\begin{array}{l}\text { Mobile } \\
\text { phase }\end{array}$ & $\begin{array}{l}\text { Run time } \\
\text { (Min) }\end{array}$ & Mean Rf & $\begin{array}{l}\text { Mean Rf } \\
\text { Escitalopram }\end{array}$ & $\begin{array}{l}\text { Standard } \\
\text { deviation } \\
\text { Citalopram }\end{array}$ & $\begin{array}{l}\text { Standard } \\
\text { Deviation } \\
\text { Escitalopram }\end{array}$ \\
\hline $\begin{array}{l}\text { toluene: } \\
\text { acetonitrile: } \\
\text { methanol }\end{array}$ & $20(\mathrm{~min})$ & 0.5188 & 0.681 & 0.00863 & 0.02779 \\
\hline $\begin{array}{l}\text { ethylacetae } \\
\text { : Butanol: } \\
\text { Ammonia }\end{array}$ & $25(\mathrm{~min})$ & 0.758 & 0.76 & 3.195 & 0.1144 \\
\hline
\end{tabular}

On the Basis of above $\mathrm{Rf}$ value and reproducible results, mean value, standard deviation, run time, it was find out that the Solvent system toluene: acetonitrile: methanol(3:3.5:3.5) is the better solvent than others for detection of citalopram by TLC and for separating the citalopram and escitalopram by TLC.

\section{UV-VIS SPECTROSCOPY}

Basic Principles: UV-VIS Spectrometry in the UV VIS REGION Is considered to be one of the oldest physical methods used for quantitative analysis and structural elucidation. The UV region extends from
$100-400 \mathrm{~nm}$. Further divided into far ultra violet region which is below $200 \mathrm{~nm}$ also known as vaccum UV another is near ultraviolet region which is $200-400 \mathrm{~nm}$ UV- Vis region extends from $400-750 \mathrm{~nm}$.

UV-VIS SPECTROPHOTOTOMETER plots a graph between the wave length versus absorbance

LAMBERT"S LAW: According to this law, the part of incident radiation absorbed by a homogenous medium is independent of the intensity of incident radiation.

Beer"s Law: According to this law the amount of incident radiation absorbed by the homogeneous 
medium is directly proportional to the concentration of molecules in it...

$\log I_{1} / I_{2}=A=a b c$

$\mathrm{I}_{1}$ IS THE INTENSITY OF Incident radiation,

$\mathrm{I}_{2}$ is the intensity of radiation transmitted Through the sample solution. A is the absorbance or optical density, $\mathrm{c}$ is the concentration of solute $(\mathrm{mol} / \mathrm{l})$ and $\mathrm{b}$ the path length in $\mathrm{cm}$.

Sample preparation: From the standard solutions 1000 ppm of citaloprams and escitalopram. $1 \mathrm{ml}$ was taken and it was diluted to $10 \mathrm{ml}$ with ethanol. Than $10 \mathrm{ml}$ solution of each citalopram and escitalopram was taken in test tube and covered it with aluminium foil.
1. Firstly, checked the calibration of UV-Visible Spectrometer by indexing it as per the norm of the protocol manual.

2. Then setup the instrument range on absorbance mode with the wavelength.

3. range between $200-400 \mathrm{~nm}$ by using Range- mode.

4. After that both the reference solvent was poured on the Quartz Cuvettes and placed it to the sample holder then set-up the Base-line w.r.t. corresponding solvents. [i.e.ethanol].

5. After set-up the base-line, scan the prepared standards individually over the range of 200-400 $\mathrm{nm}$ and recorded their corresponding spectra.

6. Compared the both of the spectrum w.r.t. their $\lambda \max \&$ pattern of spectra recorded.

\section{Qualitative Analysis}

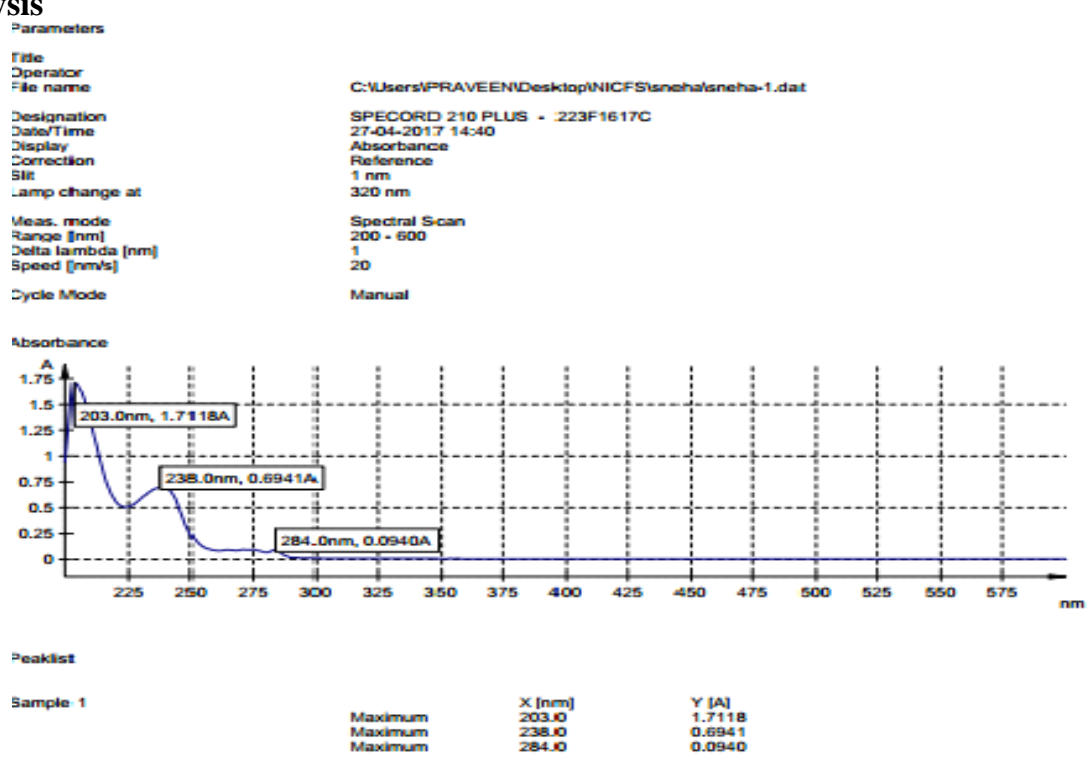

Fig. 12 Sample - Escitalopram

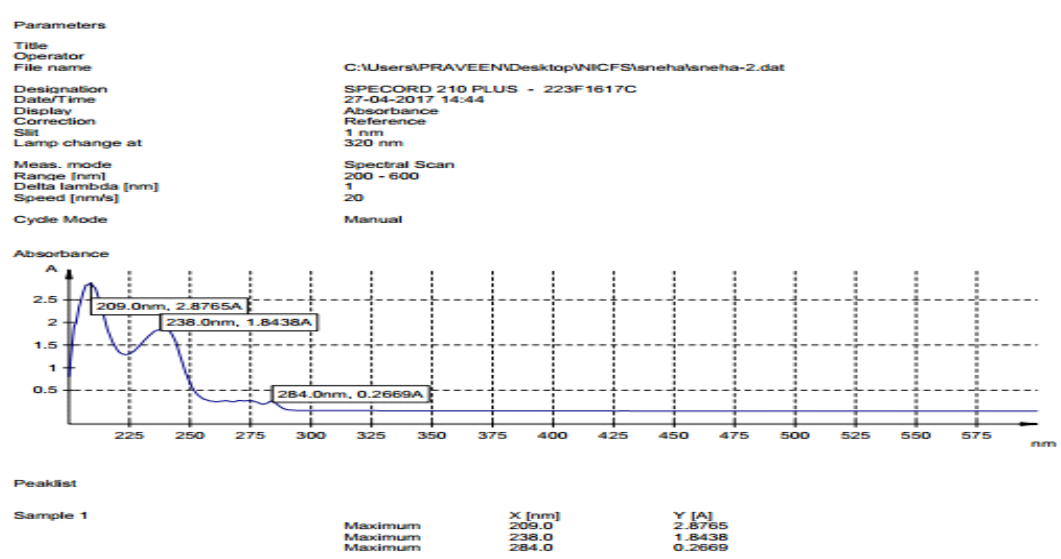

Fig.13 Sample -Citalopram

Table 5

\begin{tabular}{|c|c|r|}
\hline Samples(standard & Wavelength(nm) & Absorbance \\
\hline Escitalopram & MAX 203.0 & 1.7118 \\
& MAX 238.0 & 0.6941 \\
\hline
\end{tabular}




\begin{tabular}{|l|l|l|}
\hline & MAX 284.0 & 0.0940 \\
\hline \multirow{2}{*}{ Citalopram } & MAX 209.0 & 2.8765 \\
& MAX 238.0 & 1.8438 \\
& MAX 284.0 & 0.2669 \\
\hline
\end{tabular}

ESCITALOPRAM Shows maximum absoption at wavelengths 203.0, 238.0,284.0 with corresponding absorbance $1.7118,0.6941,0.0940$

CITALOPRAM shows maximum absorption at wavelengths 209.0,238.0,284.0 with corresponding absorbance 2.8765,1,8438,0.2669.

Gas liquid Chromatography (GLC): Gas chromatography involves separation of a mixture of volatiles by partitioning between a solid or liquid stationary phase and a gaseous mobile phase,

Gas chromatography-specifically gas liquid chromatography-involves a sample being vapourised and injected onto the head of chromatographic column. The sample is transported through the column by the flow of inhert, gaseous mobile phase.The column contains a liquid stationary phase, which is adsorbed onto the surface of an inert solid. On passing through the column volatile components impart different affinities to stationary and mobile phases and separated in fraction.

Gas liquid chromatography the stationary phase consists of solid adsorbent on which liquid material is sorbed.

\section{Instrumental components}

Carrier Gas. The carrier gas must be chemically inert. commonly used gases include nitrogen, helium, argon and carbon dioxide. The choice of carrier gas is often dependent upon the type of detector used.

Sample injection port: For optimum column efficiency the sample should be not be too large, and should be introduced onto the column as a "plug" of vapour, Slow injection of large samples causes band broadening and loss of resolution, The most common injection method is on where a micro syringe is used to inject sample through a rubber septum into a flash vapouriser port at the head of the column. The temperature of the sample port is usually about 50 higher than the boiling point of the least votalitle component of the sample. The injector can be used in two modes split or splitlesss. Split injection is used for volatile compounds or for diluting the samples, It is used in headspace method to reduce injection time. In forensic toxicology, split injection is largely used for analysis of medications, drugs of abuse and powders.

Columns: There are two general types of column, packed and capillary, Packed columns contain a finely divided, inert slid support, material coated with liquid stationary phae., Most packed columns are $1.5-10 \mathrm{~m}$ in length and have an internal diameter of $2-4 \mathrm{~mm}$.

Capillary columns have an internal diameter of few tenth of millimeter.T hese may be WCOT(Wall coated open tubular) or SCOT(support coated open tubular)

\section{Column Temperature}

This is one of the controlling factors in gas chromatographic separation, For precise work, column temperature must be controlled to within one tenths of a $\mathrm{s}$ degree. The optimum column temperature is dependent upon the boiling point of the sample.

\section{Detectors}

There are many detectors, which can be used in gas chromatography. Different detectors will give different types of selectivity. A non-selective detector respond to all compound except the carrier gas, a selective detector responds to a range of compounds with a common physical or chemical property and a specific detector responds to a particular class compounds under bthe class. detectors can also be grouped into concentration dependent detectors and mass flow dependant detectors,

The effluent from the column is mixed with hydrogen and air, and ignited. Organic compounds burning in the flame produce ions and electrons, which can conduct electricity through the flame, A large electrical potential is applied at at he burner tip and a collector electrode is located is located above flame. The current resulting from the pyrolysis of any organic compounds is measured, FID is mass sensitive rather than concentration sensitive, which gives the advantage that changes in mobile phase flow rate do not affect the detector"s response. FID is a useful general detector for the analysis of organic compounds,

Details of Instrument

Instrument- Gas Liquid Chromatogarphy (GLC)

Manufacturer- Thermofisher

Column- 2,5\% SE 30 on 80100 mesh Chromosorb G

Detector- FID

Column Temperature- $100^{\circ} \mathrm{C}-300^{\circ}$

Carrier gas nitrogen $45 \mathrm{ml} / \mathrm{min}$

Detector Temperature $-290^{\circ}$

Sample Preparation

The extracted Blood samples and Standard of citalopram were filtered through the what mann filter paper and the injection of $1 \mu \mathrm{l}$ is used for injecting the samples into the injector.

\section{Graphs 1: Gas Chromatogram Of Standard Of citalopram}




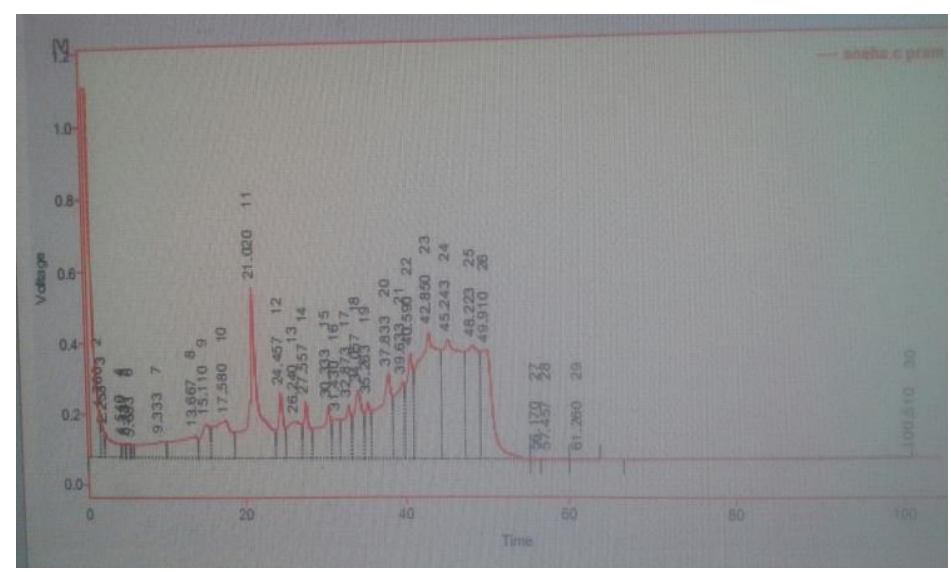

Graph 2: Gas chromatogram of blood extract

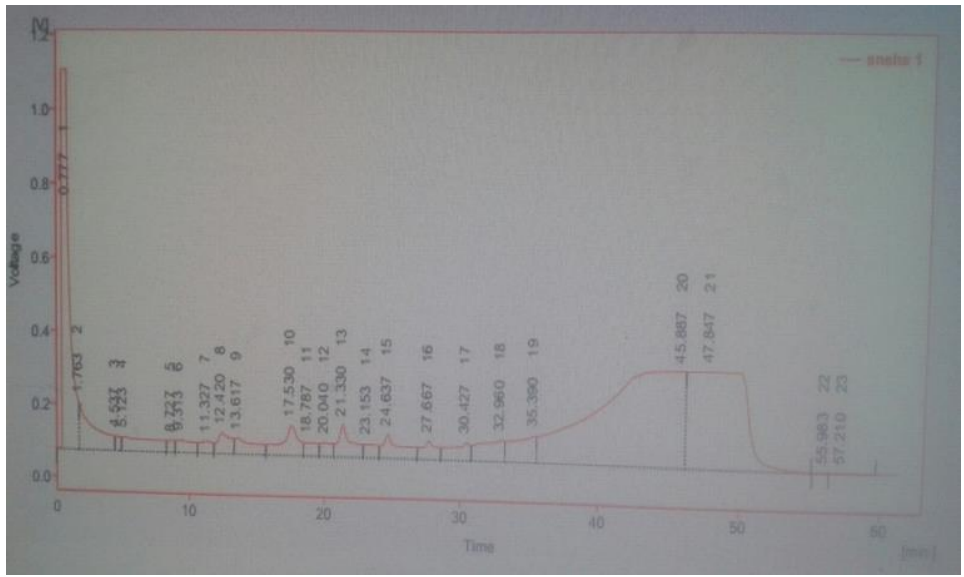

Table 7: Tabular representation of gas chromatogram of standard citalopram

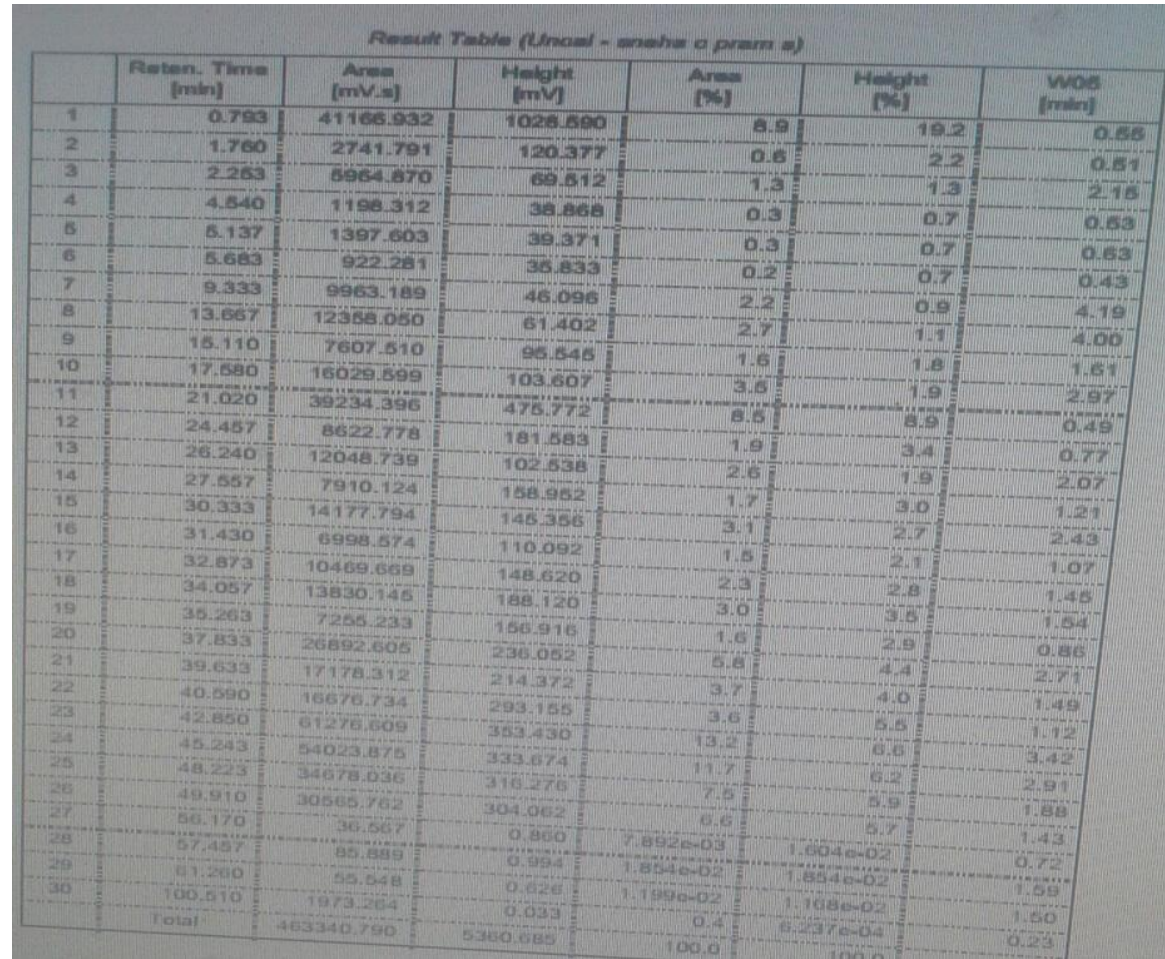

Table 8: Tabular representation of gas chromatogram of blood extract 


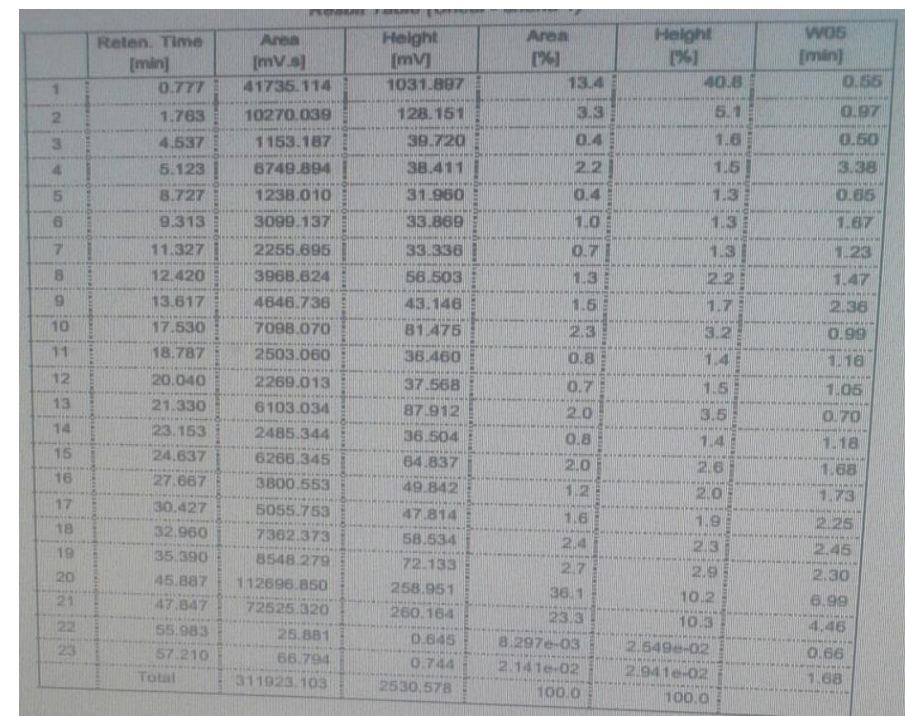

Table 9

\begin{tabular}{|l|l|l|l|}
\hline Samples & $\begin{array}{l}\text { Retention time bserved } \\
\text { for citalopram } \\
\text { (min) }\end{array}$ & $\begin{array}{l}\text { Comparable Peaks obtained at } \\
\text { (min) }\end{array}$ & $\begin{array}{l}\text { Area } \\
\text { (Mv. S) }\end{array}$ \\
\hline $\begin{array}{l}\text { Standard } \\
\text { citalopram }\end{array}$ & 21.020 & $\begin{array}{l}1,7609.333,17.680,15.110,24.457,26 \\
.24030 .333\end{array}$ & $\begin{array}{l}39234 . \\
396\end{array}$ \\
\hline $\begin{array}{l}\text { Blood } \\
\text { extract }\end{array}$ & 21.330 & $1.763,9.313,17.530,23.153$, & 6103.034 \\
\hline
\end{tabular}

Gas liquid chromatography shows comparable retention time for standard of citalopram as well as for the Blood extract which is at $21.020 \& 21.330$.This further confirms that the extracted drug was citalopram.

\section{Gas Chromatography -Mass Spectroscopy}

It is one of the hyphenated technique combining two technique wherein GC that separates chemical mixtures and a very sensitive detector (MS) wiyh a data collector (the computer component) which identify the mass ions which separate. The two instruments are joine by interface.

Once the sample solution is introduced into the GC inlet it is vaporized immediately because of high temperature (250) and swept onto the column by the carrier gas and the components are separated which pass through the MS for identification of mass ions. Thus separation and identification cum quantification are achieved simultaneously.

Sample preparation: Instrument type- GC-MS

Model No.- 6890 N Network GC System \& 5975 insert $\mathrm{XL}$

Mass -Selective Detector

Manufacturer- Agilent Technologies

U.I - FSL / Delhi/ UI/ Chem/ 07

Year of Purchase- 2007

Detector - MS-FID

Software used- MSD CHEM Station
Operating Condition of GC-MS for citalopram Drug in sample exhibits

1. Model: Agilent 6890 N Network GC system \& 5975 insert XL Mass Selective Detector

2. Column: SLB-5MS (30 m x $0.25 \mathrm{~mm})$

3. Detector: MSD / FID

4. Mode: Split mode Column

5. Oven Temp: 150-280OC

6. Detector Temp: 300 OC

7. Carrier Gas: N2

8. Hydrogen gas: $40 \mathrm{ml} / \mathrm{min}$

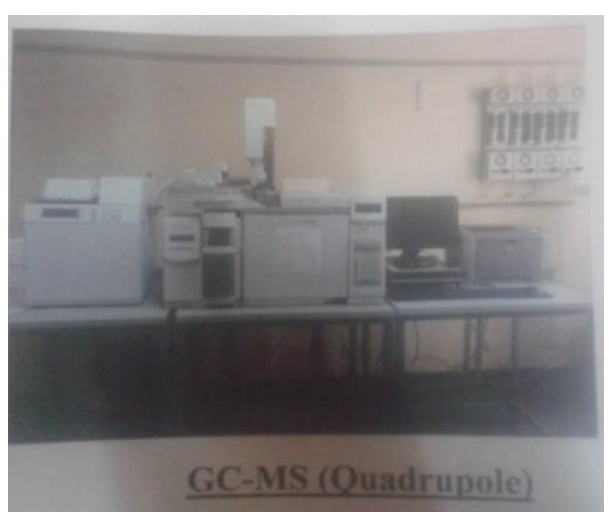

Fig. 10 


\section{Graph of Citalopram Standard}
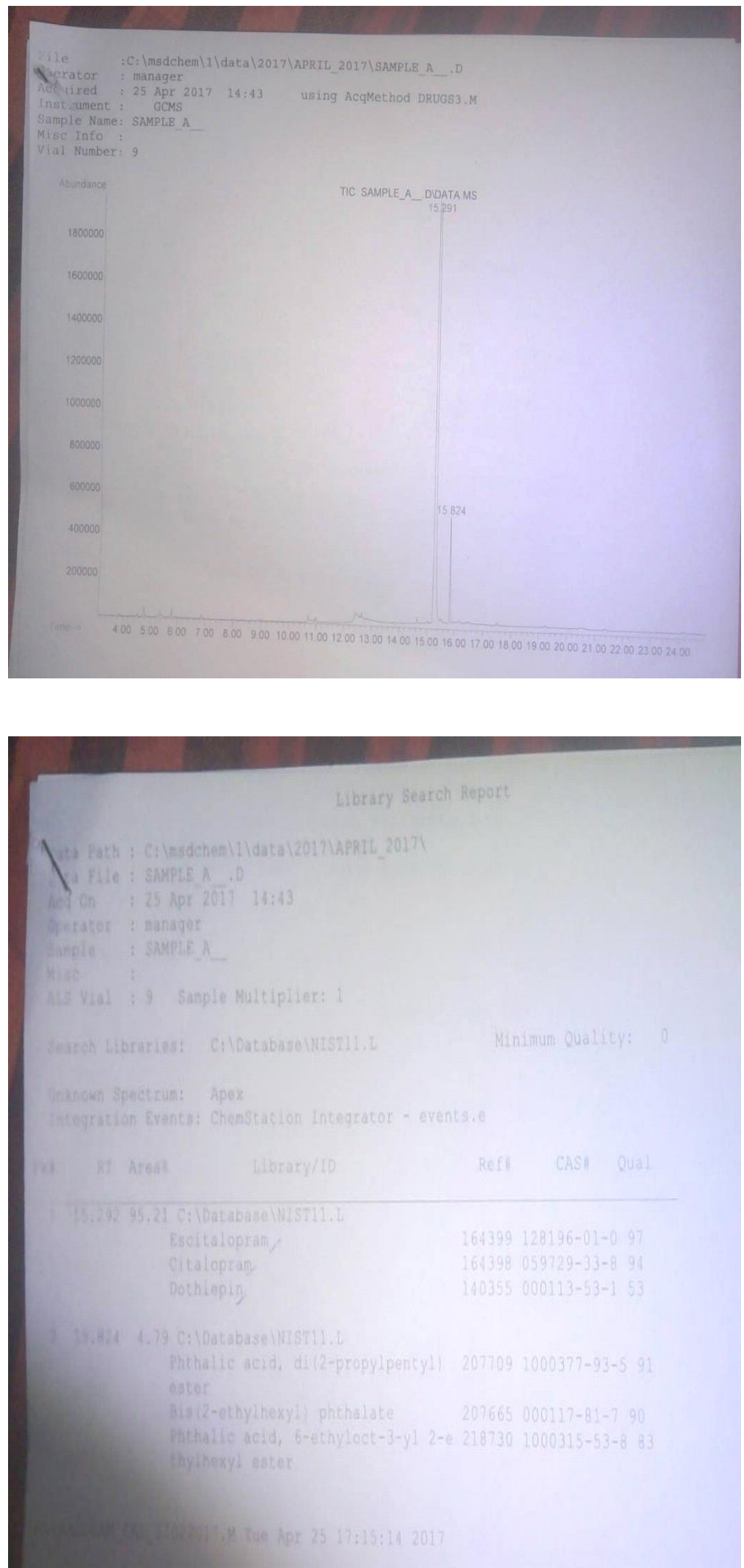

\section{Graph of Escitalopram Standard}




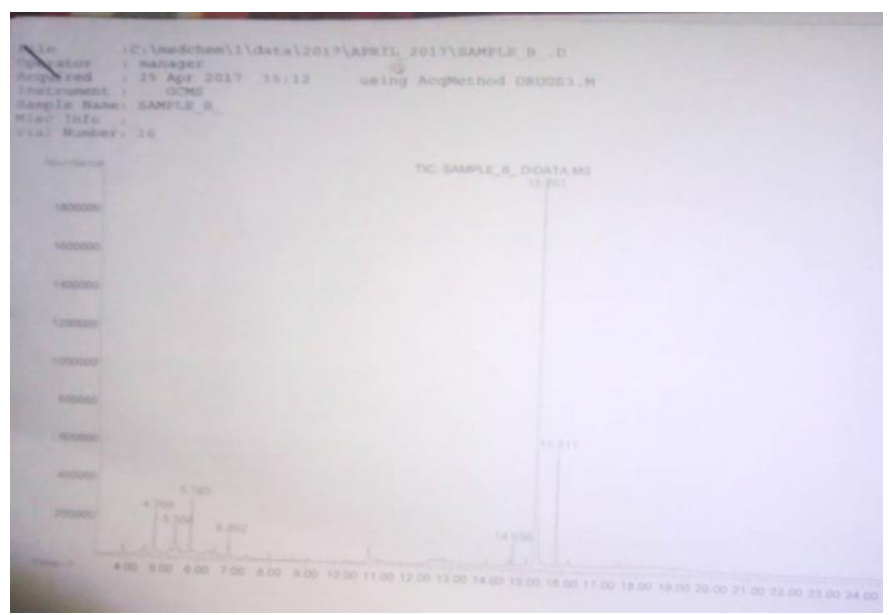

Table 6

\begin{tabular}{|c|c|c|c|c|c|}
\hline Samples & $\begin{array}{l}\text { Retention Time } \\
\text { (MIN) }\end{array}$ & $\begin{array}{l}\text { Other Peaks } \\
\text { Observed at } \\
\text { (MIN) }\end{array}$ & $\begin{array}{l}\text { Compound } \\
\text { Present }\end{array}$ & $\begin{array}{l}\text { Quantity Matches } \\
\text { with standard Library } \\
\%\end{array}$ & $\begin{array}{l}\text { Area } \\
\%\end{array}$ \\
\hline $\begin{array}{l}\text { Citalopram } \\
\text { (sample A) }\end{array}$ & 15.292 & $15.291,15.82$ & $\begin{array}{l}\text { Escitalopra } \\
\mathrm{m} \\
\text { Citalopram } \\
\text { Dotheiepin }\end{array}$ & $\begin{array}{l}97 \\
94 \\
53\end{array}$ & 95.21 \\
\hline $\begin{array}{l}\text { Escitalopram } \\
\text { (Sample B) }\end{array}$ & 15.263 & $\begin{array}{c}4.769,5.356,5.783, \\
6.862,14.656 \\
15.824\end{array}$ & $\begin{array}{l}\text { Escitalopra } \\
\mathrm{m} \\
\text { Citalopram } \\
\text { Dotheiepin }\end{array}$ & $\begin{array}{l}97 \\
94 \\
59\end{array}$ & 75.94 \\
\hline
\end{tabular}

On the basis of GC-MS graph it can be seen that both the enantiomers, citalopram,\& escitalopram shows same mass spectra which are very much similar they shows similar retention time 15.292 and 15.263. Both of them contain three compounds escitalopram, citalopram, dotheiepin with the matching probability of above $95 \%$ with the GC-MS library.
1. Color Test: Various color test were performed for the citalopram, but only marquis, mandelin, dragen-dorff, gave the positive result for citalopram.

a. Apart from that cobalt thiocyanate also gave positive result for citalopram. This suggest that this can be used for the analysis of citalopram because there is no specific test mention in literature for

\section{Results and Discussion}


citalopram however this test is also given positive by cocaine and some benzodizepenes also.

b. Cobalt thiocyanate reacts with tertiary amines present in the drug and various amines were tested (result was summarized in table no) with cobalt thiocyanate and all gave positive results depending on their concentration.

2. TLC Analysis: Various solvent system were tried in order to find new solvent system for the detection of citalopram. New solvent systems were also tried for separating the two enantiomers citalopram and escitalopram,the solvent system which shows good separation of these enantiomers were considered their $\mathrm{Rf}$ was calculated and then their mean and standard deviation were calculated. And on the basis of above calculations only these two solvent systems gave optimum results if we consider the criteria like size of spot, reproducibility, less standard deviation and acceptable Rf and also a good separation between citalopram \& escitalopram.

Toluene: acetonitrile: Methanol (3:3.5:3.5)

Ethylacetate: butanol: Ammonia (13:3:2)

For the analysis of citalopram in biological fluid or any other matrix these solvent systems can be used.

Rf value of extracted blood sample matches with the standard citalopram in these solvent system which confirms the presence of citalopram in blood extract.

UV-VIS Spectrophotometer: On comparing the wavelength (maxima) and absorbance of citalopram with the escitalopram it is observed that citaloptam show maximum absorbance 2.876 at 209.0 and escitalopram shows maximum absorbance 1.7118 at 203.0.
Table 7

\begin{tabular}{|l|c|c|}
\hline Sample & Wavelength(nm) & Absorbance \\
\hline Escitalopram & MAX 203.0 & 1.7118 \\
& MAX 238.0 & 0.6941 \\
& MAX 284.0 & 0.0940 \\
\hline Citalopram & MAX 209.0 & 2.8765 \\
& MAX 238.0 & 1.8438 \\
& MAX 284.0 & 0.2669 \\
\hline
\end{tabular}

1. Gas Liquid Chromatography(GLC): On basis of retention time and comparable peaks it can be confirmed that the recovered drug from the blood extract was citalopram.

2. Gas Chromatography-Mass Spectroscopy: Samples of citalopram and escitalopram were analyzed by GC-MS. Both the samples have shown comparable retention time $15.292 \mathrm{~min}$ and 15.693 min for citalopram and escitalopram, Both (C PRAM $S \&$ NEXITO) or (citalopram and escitalopram) having combination of escitalopram, citalopram,and dotheiepin. Sample B Escitalopram has shown some extra peaks which were not present in sample A. From the above it can be stated that for the comparison of citalopram nad escitalopram GC-MS technique is not very much helpful because both the enantiomers were having same molecular formula and that can be the reason for having similar retention time.

\section{References}

1. Vyahare janhavi R., Khedkhar T.S, Reddy Y.R, Mali B.D,,Thin layer Chromatographic Detection of Some Antidepressant Drugs commonly used in treatment of Psychiatric Disorders. Int. J of Med toxicology \& Legal Medicine. 2013;16:1.

2. Article on technical procedure for Preliminary color tests drug chemistry section issued by drug chemistry forensic scientist manager.

3. Laboratory procedure manual Forensic Toxicology, directorate of forensic science, Ministry of Home Affairs, Govt of India.2005.

4. Butler Bezchlibnyk. K, Aleksic I,Kennedy S.H, Citlopram-a review of pharmacological and clinical effects. 